\title{
A REDENÇÃO PELA ARTE EM ARIANO SUASSUNA
}

Pontifícia Universidade Católica de Minas Gerais - PUC Minas. Doutoranda. ( Bolsista Capes).
Karina de Almeida Calado

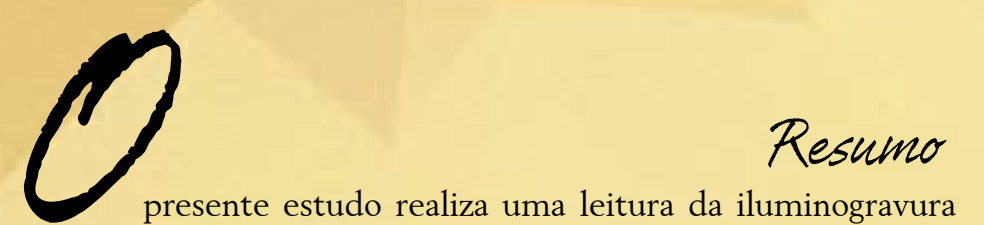

Dom, de Ariano Suassuna, à luz de noções do trágico desenvolvidas por Friedrich Nietzsche em O Nascimento da Tragédia. Parte-se do pressuposto de que essa iluminogravura, fundada na temática da morte e da redenção por meio da arte, oferece uma visão-síntese do imaginário poético de Ariano Suassuna. Sugere-se que a composição da obra está assentada na dualidade afirmada por Nietzsche: o horrível que almeja tornarse belo, enquanto arte. Tal compreensão nos leva a considerar os impulsos artísticos apolíneo e dionisíaco na análise da obra. Sob essa linha interpretativa, aponta-se que a iluminogravura Dom revela a necessidade que tem o dionisíaco (a dor, o sofrimento, o trauma da morte, a contradição e o tormento do mundo) de ser libertado por meio do apolíneo (a aparência, a beleza da arte). Nesse sentido, Nietzsche afirma que, na obra de arte, o artista celebra a sua redenção. A obra Dom apresenta características que evidenciam uma "visão trágica do mundo" em Ariano Suassuna, conforme expressa Carlos Newton Júnior, e aproximam o autor da noção de "homem trágico", considerada por Nietzsche. Além de recorrer a contribuições de Nietzsche e Newton Júnior, este trabalho está ancorado, ainda, em estudos desenvolvidos por Ângela Vaz Leão.

Palavras-chave: Ariano Suassuna. Nietzsche. Morte. Arte. Redenção.

A iluminogravura Dom integra o álbum Sonetos de Albano Cervonegro, publicado em 1985 e reproduzido, ao lado do álbum Sonetos com mote alheio, como parte integrante do Caderno de Iluminogravuras, que compõe o livro Ariano Suassuna 80, memória: catálogo e guia de fontes, publicado em comemoração aos oitenta anos de Ariano Suassuna, em 2008. Esses álbuns foram produzidos originalmente em edição artesanal, manuscrita e iluminogravada pelo próprio Suassuna. Cada álbum contém dez iluminogravuras, que medem 44 por $66 \mathrm{~cm}$, dispostas em pranchas soltas e acondicionadas em uma 
caixa de madeira. O termo iluminogravura foi concebido por Suassuna para batizar o gênero, também de sua criação, no qual integra poesia (soneto) e pintura. Trata-se de um neologismo composto pelo radical "ilumin", da palavra "iluminura", justaposto à palavra "gravura" por meio da vogal de ligação "-o" (LEÃO, 2003, p.14).

A iluminura é arte da ilustração e da ornamentação de manuscritos, desenvolvida e muito praticada na Idade Média. Aliando técnicas dessa arte aos processos modernos de gravação em papel, visando à posterior reprodução da iluminogravura em exemplares iguais, Suassuna cria gravuras para ilustrar suas composições literárias, integrando palavra e imagem em um poema plástico. Conforme Carlos Newton Júnior, as ilustrações podem aludir "ao texto integralmente, passando de episódios ou cenas descritas no poema a motivos do universo armorial, recolhidos tanto em nossa xilogravura popular quanto em arte pré-histórica" (NEWTON JÚNIOR, 1999, p. 125-126).

Na nomenclatura do gênero iluminogravura, temos a síntese do explícito amálgama entre arte medieval e arte popular nordestina como fundamento de uma arte original. Compreender o propósito de fusão entre essas duas culturas é uma chave de entrada ao projeto estético de toda a arte de Ariano Suassuna, uma vez que as aproximações entre o Romanceiro Popular Nordestino e a cultura medieval, dentre elas a presença da poética da oralidade, fundam toda a sua produção artísticoliterária.

O ideal de integração entre as artes, que está na concepção fundadora da iluminogravura, reflete a postura do autor diante dos gêneros com os quais trabalha. Há uma coerência formidável entre tudo que Suassuna faz, entre todas as produções dentro de um mesmo gênero, ou entre produções de gênero diferentes. $\mathrm{O}$ crítico Newton Júnior (1999) atribui, inclusive, o hermetismo existente na poesia de Suassuna à unidade presente em toda a sua obra. De fato, quanto mais nos inserimos no imaginário do autor e quanto mais conhecemos a sua rica produção, mais nos familiarizamos com as imagens evocadas e com a linguagem trabalhada, e, em consequência, mais propriedade de interpretação ganhamos. Newton Júnior salienta ainda que a poesia de Suassuna é a fonte profunda de toda a sua obra e exemplifica que todo um capítulo do romance A Pedra do Reino, o Folheto LVI - A Visagem da Bicha Bruzacã, é baseado num poema de sua autoria. 
Ousa-se falar em visão-síntese, ao propor a nossa análise sobre o poema Dom, porque considera-se que toda a obra de Suassuna está intimamente interligada: cada produção dialoga com o conjunto da obra. O poema "Dom" desenvolve uma temática presente no projeto artístico de uma vida inteira. Nele está presente o cruzamento entre biografia e arte, celebrando uma concepção de que a arte está entrelaçada à vida. Nesse sentido, a ideia da morte do pai, que marca a vida do autor desde sua infância, marcará também toda a sua produção artísticoliterária. Acreditamos que em toda a obra de Suassuna pode ser encontrado o princípio de aceitação da morte e de redenção por meio da arte.

Antes de proceder à leitura do poema, convém fazer breves reflexões sobre alguns estranhamentos que pautaram a leitura individual: o mote e as palavras iniciadas por maiúsculas no meio do verso.

Como é frequente na estética armorial, o poeta afirma ter desenvolvido o texto a partir de um tema ou mote "deixado" por outro autor. Assim também acontece na poesia popular nordestina, com os cordelistas, violeiros, emboladores e aboiadores. No poema Dom, Suassuna declara ter partido de um tema do poeta armorial Ângelo Monteiro.

Ao longo de todo o texto, há palavras iniciadas por letra maiúscula, como forma de valorizar palavras simbólicas. Essas palavras perdem o seu sentido comum e assumem o status de entidades e de símbolos. Algumas delas, como Dom, Morte, Sangue, Fonte, Mundo, Marca, Sono, Vida, Sol e Reino, aparecem em toda a obra de Suassuna. Parece-nos essencial notar que as palavras simbólicas se associam ou ao campo semântico da ideia de Morte (Garra, Sangue, Nefasto, Amarga, Mundo, Marca, Sono, Sol) ou ao da redenção pela arte (Dom, Fonte-sagrada, Voz, Veio, Tesouro, Vida, Bocais-de-ouro, Reino). Devemos salientar que a análise aqui apresentada, tanto do soneto quanto das gravuras que o ilustram, é uma leitura entre muitas outras possíveis.

Dom

Com Tema de Ângelo Monteiro

Se a visagem da Morte - a dura Garra -

para sempre meu Sangue penetrou,

deu-me a Fonte-sagrada, e, sem amarras,

esta Voz em meu sangue se selou.

A visão do Nefasto, sol da Amarga,

todo o sangue do Mundo envenenou. 


\section{alteros \\ ESPUC \\ BELO HORIZONTE - N. $28-2016$}

\section{KarINa flmeIDA（aLADO}

Nunca mais fui o mesmo, pois a Marca, ao sol cruel do Sono, me apontou.

Mas, se fui para sempre assinalado, achei o Veio, a chama do Tesouro, que a Morte é sonho, a Vida é fogo e treino.

E, se o selo do Sol me tem, marcado, me deu o Dom de, em três Bocais-de-ouro, fazer ouvir as trompas do meu Reino.

Neste estudo, não será possível fazer uma leitura intersemiótica da iluminogravura. Entretanto, achamos conveniente ilustrá-la aqui para termos uma noção de como o soneto está disposto nela:

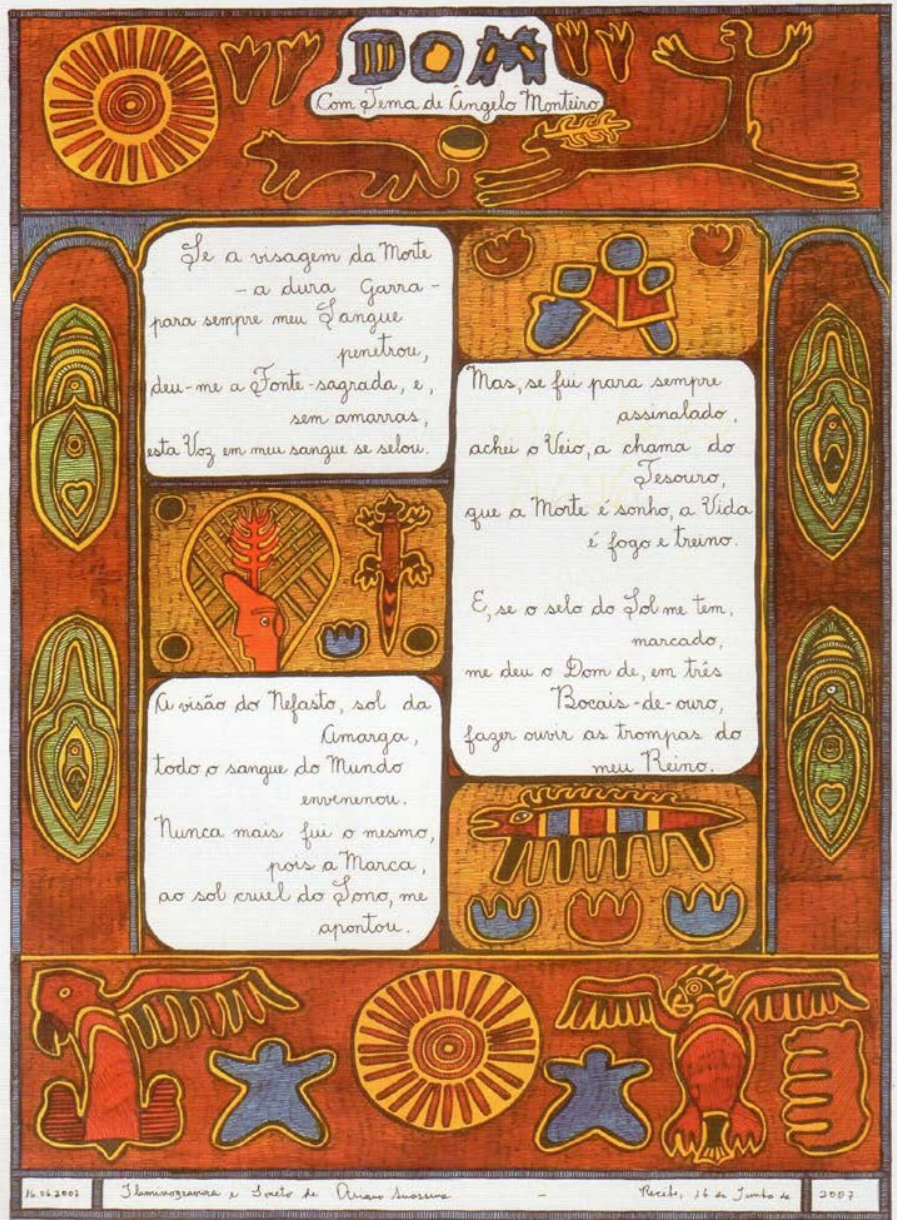

Do ponto de vista da composição formal do poema, trata-se de um soneto italiano (dois quartetos seguidos de dois tercetos). Os quatorze versos são decassílabos e as rimas são alternadas, dispostas em $a-b-a-b$, nos quartetos, com pequenas variações fonéticas nos versos ímpares (-arra/ -arras e -arga/ -arca); e 


\section{adenows \\ ESPUC \\ BELO HORIZONTE - N. $28-2016$}

c-d-e, nos tercetos, correspondentes às rimas -ado, -ouro e -eino.

Partindo do título do poema, compreende-se que a palavra "Dom" pode ser interpretada como dádiva. A morte marca profundamente o eu poético, mas compensa sua marca dandolhe a fonte, o talento, para, na arte, superá-la. Pensamos que o verbo "dar", empregado por duas vezes ao longo do poema, apresenta-se como compensação para a marca da morte, e confirma a nossa escolha interpretativa. No entanto, como associamos a aparência da iluminogravura à imagem simplificada (ou estilizada) da estrutura externa de um castelo, podemos interpretar a palavra "Dom" como o título de nobreza mais alto do reino, o equivalente ao de rei.

O poema é essencialmente metalinguístico. Ao mesmo tempo em que a temática da morte é desenvolvida no texto, a voz poética assinala que a temática também serve como fonte para a composição de toda a obra do autor.

No primeiro verso do soneto "Dom", o poeta nos traz a primeira metáfora para a morte, que é sugerida como "a dura Garra". Está explícita a ideia de tornar o substantivo abstrato Morte em uma imagem concreta: "a dura Garra". Conforme Leão (2003, p. 15), a escolha de signos linguísticos que representem "imagens concretas, de contornos nítidos e firmes" é recorrente na literatura de Ariano Suassuna.

"A dura Garra" é uma metonímia possível para ave de rapina ou para felino, uma vez que garra é uma acepção semântica para as unhas desses animais. Cabe-nos considerar que essa metáfora, reconstruída pelo sentido metonímico, é muito comum no imaginário suassuniano. A morte, em muitas ocorrências da produção do autor, é mimetizada como aves de rapina e felinos, a exemplo do gavião, da acauã e da onça. Podemos ilustrar tais argumentos recorrendo, intertextualmente, a dois poemas de Suassuna: "A Morte - A Moça Caetana" e "O Sol de Deus". No primeiro exemplo, em que a Moça Caetana é mais uma metáfora para a morte, maneira como também é representada no imaginário sertanejo, Suassuna descreve e grava a Moça Caetana encenando-a com um gavião na fronte. Do mesmo modo, no poema "O Sol de Deus", a imagem da morte é construída, dentre outras, no primeiro terceto, como uma mulher em que também se faz presente a imagem de um gavião: 
Ela virá-Mulher-aflando as asas, com o mosto da Romã, o sono, a Casa, e há de sagrar-me a vista o Gavião

A imagem da morte é transfigurada na imagem de um predador, com a qual a voz poética sugere que ela é a predadora universal, a que vitima a todos os seres, da qual não se escapa, não se pode fugir.

O segundo verso, "para sempre meu Sangue penetrou", apresenta duas compreensões que se complementam: uma que sugere a referência à morte do pai, como fato que marca a biografia do poeta, tendo na palavra "Sangue" a sinonímia do laço familiar; e uma segunda compreensão, indicando que esse fato biográfico pulsará eternamente em suas veias, assinalando a sua existência. Notemos que "Sangue" é uma palavra que denota o princípio da vida. A palavra adotada para a ação frasal é o verbo "penetrar", com o qual, percebemos a ideia de que "a visagem da Morte" está entranhada em seu íntimo e permanecerá durante toda a sua vida.

Na sequência, a voz poética evidencia uma aceitação da ideia da morte, que é feita de modo afirmativo, isenta de pessimismo. A morte é deslocada para a condição de matéria do fazer artístico. É a "Fonte-sagrada", o estado de poesia, o impulso criador. A arte revela-se ao homem como a melhor vingança sobre a morte, a sua vitória, ou, numa interpretação nietzschiana, o seu consolo metafísico. A "Fonte-sagrada" é o âmago de onde emana todo o repertório, que, livre, sem imposições ou limites, torna-se "Voz", ao transfigurar a dor, o horrível, a inquietação que atravessa a sua existência, na beleza de seu canto. Essa fonte está necessariamente marcada pela dualidade: o horrível que almeja tornar-se belo, enquanto arte. Nesse sentido, a primeira estrofe nos remeteria à necessidade de o dionisíaco ser libertado por meio do apolíneo. Para Nietzsche (1999), o artista está destituído de sua vontade individual, tornandose um medium entre o impulso criador (a fonte) e a obra (a aparência). Na obra, o artista celebra a sua redenção.

Compreendemos que, já a partir dessa primeira estrofe, é possível identificarmos algumas noções do trágico apontadas por Nietzsche (1999). Consideramos que a nossa interpretação converge com a caraterização feita por Newton Júnior (1999), que aponta "a visão trágica do mundo", ou "sentimento trágico da vida”, na obra de Suassuna. 
Nietzsche (1999) considera que a vida possui uma destinação trágica. Segundo ele, o mundo, a vida em si, não fazem sentido, e essa constatação nos conduz à resignação. A arte seria o mecanismo necessário para se viver, para se suportar a existência. Para o filósofo, o homem é "salvo pela arte, e através da arte salva-se nele - a vida" (1999, p. 55). Assim, no trabalho incessante de criação das belas formas, o homem se redime do sofrimento, sem precisar negar a vida.

De acordo com Nietzsche (1999), a existência e o mundo só podem justificar-se eternamente como fenômenos estéticos. Desse modo, Suassuna seria o homem trágico proposto pelo filósofo, aquele ser que é capaz de justificar a sua existência na transfiguração do sofrimento.

Nietzsche (1999), a partir do estudo da tragédia grega, considera que a arte conta, em sua origem, com os deuses Apolo e Dionísio unidos, após prolongada luta prévia. Esses deuses são pensados como universos ou impulsos artísticos perceptíveis na natureza. Apolo, deus da luz, imagem divina da ordem, da medida e da harmonia. Dionísio, o deus da escuridão, do caos, da desmesura. Apolo seria o responsável por dar forma, em bela aparência, aos impulsos dionisíacos. Na visão grega, todo sujeito experimenta o sofrimento, o horror, e tem o seu íntimo marcado por imagens sombrias, tristes e escuras, da mesma forma que também experimenta imagens agradáveis. $\mathrm{Na}$ aparência da beleza apolínea, reverbera a eterna dor primordial. Vejamos o que o filósofo nos diz sobre a necessidade de existência mútua desses deuses, união fundamental à atividade criadora:

[...] quanto mais percebo na natureza aqueles onipotentes impulsos artísticos e neles um poderoso anelo pela aparência [Schein], pela redenção através da aparência, tanto mais me sinto impelido à suposição metafísica de que o verdadeiramente-existente [Wahrhaft-Seiende] e Uno-primordial, enquanto o eternopadecente e pleno de contradição necessita, para a sua constante redenção, também da visão extasiante, da aparência prazerosa [...] (NIETZSCHE, 1999, p. 39).

A obra de Suassuna nos coloca exatamente diante dessa visão dialética, da inseparabilidade e inescapabilidade dos opostos. O eu poético em "Dom" tem ciência de que não é possível a correção da existência e, diante disso, aceita o seu destino, sabendo, ao mesmo tempo, que é detentor de mecanismos para transfigurá-lo. Tal percepção nos conduz ao conceito 
do apolíneo sugerido por Barbosa (2011, p. 14-15), em sua interpretação da obra nietzschiana. Para esse estudioso, o apolíneo é a "forma encontrada para a aceitação daquele lado da existência considerado escuro, insuportável, aterrador", o impulso responsável por transfigurar o "aspecto ameaçador em algo suportável a todo vivente. [...] a disposição formal do informe, a ordenação do caos".

Ainda quando apontamos a presença da vida de Suassuna em sua obra, estamos diante de uma concepção de arte trágica dos gregos de que vida e arte estão intimamente ligadas, em conflito e equilíbrio constantes. A perspectiva de Reino literário, construída em toda a obra do autor, aproxima-se do "consolo metafísico", essencial à tragédia grega, definido magistralmente por Nietzsche nas seguintes considerações: "a alegria metafísica com o trágico é uma transposição da sabedoria dionisíaca instintivamente inconsciente para a linguagem das imagens". (NIETZSCHE, 1999, p. 101-102).

No segundo quarteto, observamos que o eu poético encena não só o seu infortúnio, mas também a destinação trágica de todo o mundo: a consciência da mortalidade. Temos, nos dois primeiros versos do quarteto, a representação da queda do homem do paraíso e, por sua vez, a perda da inocência e a tomada de conhecimento de que é um ser que nasce para morrer. A marca da morte faz parte da existência humana desde a sua concepção original. A queda do paraíso é, portanto, a peripécia original da humanidade. Não é aleatório o emprego do verbo envenenar. Pensamos tratar-se de uma clara referência ao veneno da serpente, símbolo do conhecimento e representação alegórica do demônio que tentou Adão e Eva no Éden. O veneno é uma substância que penetra na circulação sanguínea e altera a composição química do ser. Assim como o chamado "pecado original", esse veneno também vai deixar a sua marca nos descendentes de Adão, ou, como sugerido no poema, em toda a humanidade.

O terceiro e o quarto versos do segundo quarteto se referem à peripécia pessoal. O poeta é expulso de seu paraíso: o universo da infância. A consciência da mortalidade humana lhe vem da maneira mais dolorosa: o brutal assassinato de seu pai. Toda a trajetória de felicidade é transformada no seu contrário.

Nesse segundo quarteto há um diálogo muito intenso com os sonetos "Infância" e "Abertura" "sob pele de ovelha", dos quais destacamos, em especial, o primeiro terceto e o segundo 


\section{adenows \\ ESPUC \\ BELO HORIZONTE - N. 28 - 2016}

\section{KarINa flmeIDA（aLADO}

quarteto desses poemas, respectivamente:

E veio o Sonho: e foi despedaçado.

E veio o Sangue: o Marco iluminado, a luta extraviada e a minha Grei.

Eu, forçado a ascender, eu, Mutilado, busco a Estrela que chama, inapelável. E a Pulsação do Ser, Fera indomável, arde ao sol do meu Pasto - incendiado.

A peripécia, característica essencial da tragédia, é o mais forte laço entre os trechos e torna-se mais um exemplo da manifestação do trágico na obra do autor. Essa ponte pode ser observada com muita clareza nos seguintes exemplos: em "Dom", o eu poético é apontado "ao sol cruel do Sono"; em "Infância", o sonho, ou paraíso, é despedaçado; em "Abertura" "sob pele de ovelha" o eu poético se vê como Mutilado; e, de acordo com a leitura de Newton Júnior (1999), o pasto, que era verde, incendeia-se.

Percebamos que a vida do Autor é marcada pela peripécia, mas, assim como esta é essencial à tragédia grega, ela se torna fonte da poesia de Suassuna, condição primordial para sua existência. Há um movimento de busca pela inversão, o desejo de vingança contra a desgraça; algo que só é alcançável ao ser humano por meio da arte. Se da fortuna bruscamente veio o infortúnio, há o desejo de, na arte, reconstruir-se o reino destruído na vida empírica.

O primeiro terceto do poema "Dom" se inicia com a conjunção adversativa "mas". Essa marca gramatical evidencia uma mudança de sentido em relação à estrofe imediatamente anterior. Como expusemos acima, a temática da "queda" predomina na segunda estrofe. A terceira estrofe, então, opõese a ela para retomar a temática da compensação da morte por meio da arte, desenvolvida na primeira estrofe.

$\mathrm{Na}$ existência marcada pela morte, o eu poético encontra a base, a causa primeira de sua criação, o tesouro de seu Reino, sugerido nos seguintes versos: "Mas, se fui para sempre assinalado,/ achei o Veio, a chama do Tesouro". No verso que fecha o primeiro terceto, "que a Morte é sonho, a Vida é fogo e treino", pensamos estar diante de uma imagem basilar ao universo suassuniano. Sugerimos que a imagem evocada em "a Morte é sonho" remete ao sonho de Quaderna, em "A Visagem da Onça Caetana", capítulo d'A Pedra do Reino. Quaderna, 
esperando o interrogatório do Corregedor, adormece numa espreguiçadeira e sonha com a Moça Caetana passando o dedo na parede, de onde ia surgindo um texto. Esse texto é entendido por Suassuna como a origem de todo o romance A Pedra do Reino.

Por aproximação, acreditamos que o sonho é uma alusão à passagem bíblica, no Livro do Profeta Daniel, capítulo 5, no qual o rei dos caldeus, Belsazar, vê uma mão escrevendo palavras enigmáticas na caiadura do palácio real. O rei mandou chamar o Profeta Daniel, cativo do reino e conhecido por sua inteligência e sabedoria, para decifrar o enigma. Daniel revela que o enigma foi escrito pelas mãos de Deus e que se trata da mensagem que anuncia o final do reino dos caldeus com a morte de seu rei. Além disso, a imagem de Daniel, enquanto profeta e decifrador de enigmas, pode estar associada a um espelhamento do Autor. Também "A Visagem da Onça Caetana" é um anúncio da morte do rei, no caso, o pai de Suassuna, e a consequente destruição de seu reino. O final do verso "A Vida é fogo e treino" lembra à expressão latina fiat lux, que, aliada ao trabalho intenso, é condição indispensável à atividade criadora, que dá sentido à vida.

Na última estrofe, "E, se o selo do Sol me tem, marcado,/ me deu o Dom de, em três Bocais-de-ouro,/ fazer ouvir as trompas do meu Reino", o poeta se vale de uma construção metafórica, "três Bocais-de-ouro", para evidenciar o dom de escrever com maestria nos três grandes gêneros literários (o épico, o lírico e o dramático). A literatura de Suassuna, ao mesmo tempo que marcada pela morte de seu pai, é a pedra com a qual ele reergue o Reino destruído e assume o trono deixado vago. $\mathrm{O}$ soar das trompas de seu Reino representam a vitória de sua arte contra a morte.

\section{REDEMPTION THROUGH ART IN ARIANO SUASSUNA}

\section{ABSTRACT}

This study does a reading of Dom, an iluminogravura by Ariano Suassuna, in the light of the notions of the tragic developed by Friedrich Nietzsche in The Birth of Tragedy (1999). We assume that this iluminogravura, 
based on the thematics of death and redemption through art, offers a synthetic view of Ariano Suassuna's poetic imaginary. It is suggested that the composition of the work of art is laid on the duality stated by Nietzsche: the horrible that longs to become beautiful, while being art. Such understanding leads us to consider the Apollonian and Dionysian artistic impulses in the analysis of the work of art. In this interpretative line, we point out that the iluminogravura Dom reveals the need that the Dionysian impulse (the pain, the suffering, the trauma of death, the contradiction and the torment of the world) has to be liberated by the Apollonian (the appearance, the beauty of art). In this sense, Nietzsche asserts that, in the work of art, the artist celebrates his redemption. The work Dom presents some characteristics that evince a "tragic view of the world" in Ariano Suassuna, as expressed by Carlos Newton Júnior (1999), and approximates the author to the notion of the "tragic man", as considered by Nietzsche. In addition to Nietzsche's and Newton Júnior's contributions, this work is also anchored in studies developed by Ângela Vaz Leão (2003).

Keywords: Ariano Suassuna. Nietzsche. Death. Art. Redemption.

\section{REFERÊNCIAS}

BARBOSA, Ildenilson Meireles. Arte trágica, pessimismo e redenção, $\mathbf{O}$ nascimento da tragédia. Trilhas Filosóficas, Caicó/ RN, ano IV, n. 2, p. 9-19, 2. sem. 2011.

LEÃO, Ângela Vaz. A tigre negra: uma iluminogravura de Ariano Suassuna. Scripta, Belo Horizonte, v. 7, n. 13, p. 13-24, 2. sem. 2003.

NEWTON JÚNIOR, Carlos (Org.). Ariano Suassuna 80, memória: catálogo e guia de fontes. Rio de Janeiro: Sarau, 2008.

NEWTON JÚNIOR, Carlos. O pai, o exílio e o reino: a poesia armorial de Ariano Suassuna. Recife: Ed. Universitária da UFPE, 1999.

NIETZSCHE, Friedrich Wilhelm. O nascimento da tragédia, ou helenismo e pessimismo. 2. ed. 3. reimpressão. Tradução, notas e posfácio J. Guinsburg. São Paulo: Companhia das Letras, 1999.

Recebido em: 26/06/2015 